\title{
Study of plasma and red cell phospholipid fatty acids in extrahepatic cholestatic jaundice
}

\author{
M W Scriven, D F Horrobin, M C A Puntis
}

\begin{abstract}
The poor outcome in patients with extrahepatic cholestatic jaundice seems in some way related to reticuloendothelial dysfunction. Similar dysfunction can be caused by abnormal tissue phospholipid fatty acid patterns. Little is, however, known about such patterns in extrahepatic cholestatic jaundice. The phospholipid fatty acid patterns in 42 controls were compared with 42 patients with extrahepatic cholestatic jaundice. Many abnormalities were found. The general pattern was of a fall in polyunsaturated fatty acids and a rise in monounsaturated fatty acids, with a consequent fall in the double bond index (mean number of double bonds per fatty acid) showing an overall rise in saturation. All three major substrates for eicosanoid production were reduced in the jaundiced group. The changes seemed to be associated with jaundice itself, rather than the cause of the jaundice. The central roles of fatty acids in the determination of membrane function and in the provision of substrates of eicosanoid production, mean that these changes may explain some of the reticuloendothelial dysfunction found in extrahepatic cholestatic jaundice.
\end{abstract}

(Gut 1994; 35: 987-990)

For many years patients with extrahepatic cholestatic jaundice have suffered high surgical complication rates. ${ }^{12}$ Although recent reports suggest these may be falling, ${ }^{3}$ the explanation for the excess morbidity and mortality is unclear. The reticuloendothelial system seems important in these excess complications. Dysfunction of the fixed reticuloendothelial system seems to permit 'spillover' of endotoxins. The most important complications have been associated with systemic endotoxaemia. Many abnormalities in reticuloendothelial system function have been shown in extrahepatic cholestatic jaundice. ${ }^{4-8}$

The essential fatty acids are polyunsaturated fatty acids of two families - the n- 6 series derived from dietary linoleic acid (18:2n-6) and the $n-3$ series derived from dietary $\alpha$ linolenic acid (18:3n-3). The important roles of these fatty acids seem to be as the precursors of the oxygenated fatty acids, the eicosanoids, and as structural elements of lipid membranes. ${ }^{9}$ Their influence on membrane function and eicosanoid production, mean that abnormalities in tissue fatty acid patterns are possible causes of the reticuloendothelial system dysfunction that occurs in extrahepatic cholestatic jaundice.

Little is known, however, about tissue fatty acid patterns in extrahepatic cholestatic jaundice and this study aimed at establishing them.

\section{Methods}

Forty two patients with extrahepatic cholestatic jaundice (group 2) were compared with 42 matched controls (group 1). Group 1 comprised patients admitted for surgery for benign conditions; none had any history of hepatobiliary disease and all had normal liver function tests. All the jaundiced patients had large duct extrahepatic biliary obstruction. None of the patients in either group had any condition or propensity known to influence fatty acid concentrations such as diabetes mellitus or an atopic tendency.

Venous blood was drawn before operation, in group 1, and before any procedure to relieve jaundice, in group 2 . The possible effects of diurnal variation and platelet aggregation on fatty acid values, were avoided by taking blood in the morning with large bore needles, without using a tourniquet. The patients did not fast before venesection. The blood was
Hepato-PancreaticoBiliary Surgery Unit, University of Wales College of Medicine Cardiff

M W Scriven

M C A Puntis

Efamol Research Institute, Kentville, Nova Scotia, Canada D F Horrobin

Correspondence to Mr M Scriven, 24 Rhiwlas, Cardiff CF4 9AD.

Accepted for publication 10 November 1993
TABLE I Study groups

\begin{tabular}{llllll}
\hline & Sex & $\begin{array}{l}\text { Age } \\
\text { Median (range) }\end{array}$ & $\begin{array}{l}\text { Weight (kg) } \\
\text { Mean }(95 \% \mathrm{CI})\end{array}$ & $\begin{array}{l}\text { Bilirubin } \\
\text { (micromoll) } \\
\text { Mean (range) }\end{array}$ & $\begin{array}{l}\text { ALP (IUI) } \\
\text { Mean (range) }\end{array}$ \\
\hline $\begin{array}{l}\text { Group 1: controls } \\
(\mathrm{n}=42)\end{array}$ & $23 \mathrm{M}: 19 \mathrm{~F}$ & $63(37-87)$ & $70 \cdot 8(66 \cdot 6$ to $75 \cdot 1)$ & & \\
$\begin{array}{l}\text { Group 2 } \\
(\mathrm{n}=42)\end{array}$ & $23 \mathrm{M}: 19 \mathrm{~F}$ & $69(22-88)$ & $67 \cdot 8(62 \cdot 9$ to $72 \cdot 8)$ & $247(39-540)$ & $823(233-3060)$ \\
$\begin{array}{c}\text { Group 2 subgroups } \\
\text { Benign patients } \\
(\mathrm{n}=12)\end{array}$ & $5 \mathrm{M}: 7 \mathrm{~F}$ & $71(23-88)$ & $66 \cdot 7(58 \cdot 3$ to $75 \cdot 0)$ & $136(50-492)$ & $625(233-1480)$ \\
$\begin{array}{l}\text { Malignant patients } \\
(\mathrm{n}=30)\end{array}$ & $18 \mathrm{M}: 12 \mathrm{~F}$ & $68(24-85)$ & $68 \cdot 2(61 \cdot 9$ to $74 \cdot 6)$ & $292(39-540)$ & $902(353-3060)$ \\
\hline
\end{tabular}

Using a two sample Student's $t$ test no statistical difference was found between the weights or ages of the two groups. $95 \%$ CI - 95\% confidence intervals. ALP - alkaline phosphatase (normal range 40-140 IU/1)). Normal range for plasma bilirubin 5-17 micromol/. None of the patients in group $1 \mathrm{had}$ abnormal bilirubin or alkaline phosphatase values. 
TABLE II Results for plasma phospholipids

\begin{tabular}{|c|c|c|c|c|c|c|}
\hline & \multicolumn{2}{|c|}{ Group 1: controls $(n=42)$} & \multicolumn{2}{|c|}{ Group 2: jaundiced $(n=42)$} & \multirow[b]{2}{*}{$p$} & \multirow[b]{2}{*}{$\begin{array}{l}\text { Ratio of } \\
\text { jaundice: control }\end{array}$} \\
\hline & Mean & $\begin{array}{l}95 \% \text { Confidence } \\
\text { intervals }\end{array}$ & Mean & $\begin{array}{l}95 \% \text { Confidence } \\
\text { intervals }\end{array}$ & & \\
\hline $16: 0$ & $28 \cdot 58$ & (27.69 to 29.47$)$ & $31 \cdot 60$ & $(30.75$ to 32.44$)$ & $<0.001$ & $1 \cdot 11$ \\
\hline $18: 0$ & 9.92 & $(9 \cdot 20$ to $10 \cdot 65)$ & $8 \cdot 35$ & $(7 \cdot 49$ to $9 \cdot 22)$ & $<0.010$ & 0.84 \\
\hline $18: 1 n-9$ & $12 \cdot 32$ & (11.85 to 12.79 ) & $16 \cdot 47$ & (15.61 to 17.34$)$ & $<0.001$ & 1.34 \\
\hline $18: 2 n-6$ & $24 \cdot 62$ & (23.44 to 12.79$)$ & $21 \cdot 74$ & (20.62 to 22.86 ) & $<0.001$ & $0 \cdot 88$ \\
\hline $20: 2 n-6$ & $0 \cdot 26$ & $(0.18$ to 0.35$)$ & 0.21 & $(0.15$ to 0.27$)$ & NS & $0 \cdot 80$ \\
\hline $20: 3 n-6$ & 3.09 & (2.83 to 3.35$)$ & $2 \cdot 01$ & $(1.78$ to 2.24$)$ & $<0.001$ & 0.65 \\
\hline $20: 4 n-6$ & $10 \cdot 63$ & $(9.85$ to 11.41$)$ & 8.99 & ( $8 \cdot 19$ to $9 \cdot 78)$ & $<0.005$ & 0.85 \\
\hline $22: 4 n-6$ & $0 \cdot 23$ & $(0.16$ to 0.30$)$ & $0 \cdot 17$ & $(0.10$ to 0.23$)$ & NS & 0.71 \\
\hline $20: 5 n-3$ & $1 \cdot 60$ & $(1.16$ to 2.04$)$ & 0.84 & $(0.70$ to 0.97$)$ & $<0.001$ & 0.52 \\
\hline $22: 5 n-3$ & 0.99 & $(0.87$ to 1.11$)$ & 0.57 & $(0.47$ to 0.67$)$ & $<0.001$ & 0.58 \\
\hline $22: 6 n-3$ & $4 \cdot 84$ & $(4 \cdot 31$ to $5 \cdot 37)$ & $4 \cdot 07$ & ( 3.70 to 0.45$)$ & 0.020 & 0.84 \\
\hline SFA & $38 \cdot 86$ & (37.66 to 40.05$)$ & $40 \cdot 32$ & $(39.29$ to 41.36$)$ & NS & 1.04 \\
\hline MUFA & $13 \cdot 51$ & $(13.02$ to 14.01$)$ & $19 \cdot 31$ & (18.20 to 20.42 ) & $<0.001$ & 1.43 \\
\hline PUFA & 46.90 & $(45.48$ to 48.32$)$ & $39 \cdot 45$ & (37.76 to $41 \cdot 14$ ) & $<0.001$ & 0.84 \\
\hline DBI & $1 \cdot 60$ & $(1.54$ to 1.66$)$ & $1 \cdot 40$ & $(1.35$ to 1.46$)$ & $<0.001$ & 0.88 \\
\hline Total (n-6) & 39.03 & (37.73 to 40.33 ) & $33 \cdot 34$ & (31.91 to 34.76 ) & $<0.001$ & 0.85 \\
\hline Total $(n-3)$ & $7 \cdot 83$ & (6.90 to 8.77$)$ & 6.09 & $(5.56$ to 6.61$)$ & $<0.005$ & 0.78 \\
\hline 18-carbon-PUFA & $25 \cdot 07$ & (23.90 to 26.25$)$ & $22 \cdot 38$ & (21.24 to 23.52$)$ & $<0.001$ & 0.89 \\
\hline 20-carbon-PUFA & $15 \cdot 62$ & (14.60 to 16.65$)$ & $12 \cdot 07$ & $(11.10$ to 13.05$)$ & $<0.001$ & $0 \cdot 77$ \\
\hline 22-carbon-PUFA & $7 \cdot 19$ & $(6.55$ to 7.83$)$ & $5 \cdot 56$ & $(5.03$ to 6.09$)$ & $<0.001$ & 0.77 \\
\hline
\end{tabular}

All results shown are molar percentages, except double bond index (DBI), which has no units. The values of $p$ result from two sample Student's $t$ tests between groups 1 and 2. The ratios shown are the ratios of the means for group 2 to those for group 1. SFA = saturated fatty acids, MUFA = monounsaturated fatty acids, PUFA = polyunsaturated fatty acids, NS $=p>0.05$.

separated by centrifugation, into plasma and red cells, and stored at $-70^{\circ} \mathrm{C}$ until analysis. Under these conditions such samples are stable for many months (unpublished data).

Analysis was done in a standard fashion for the plasma and the red cells. Lipid was extracted, and the phospholipid fraction separated and extracted by thin layer chromatography. The fatty acids within the phospholipid fraction were methylated and assayed by fully automated packed column gas liquid chromatography. All these methods have been described previously. ${ }^{10}$ The results, expressed as molar percentages, ${ }^{9}$ were transferred to a microcomputer, on which data manipulation and analysis were done.

A number of variables, calculated from the fatty acid results, can be used to help with the interpretation of the fatty acid states. ${ }^{9}$ These were calculated from the results and analysed statistically. The double bond index is the mean number of double bonds per fatty acid. The other variables are totals for various groups of fatty acids, for instance total $n-6$ polyunsaturated fatty acids and total 20-carbon polyunsaturated fatty acids. It should be noted that in humans, there are negligible quantities of non-n-6, non-n-3 polyunsaturated fatty acids in these fractions. Essential fatty acids and polyunsaturated fatty acids are thus, in effect, equivalent.

Two sample Student $t$ tests were used to compare the two groups, producing a large number of comparisons. This is the only satisfactory way of comparing fatty acid data. Fatty acid states cannot be measured by a single variable - many variables must be considered together. To our knowledge, no simple method around this problem has been devised.

\section{Results}

In each group there were 23 men and 19 women. The groups were well matched for age and weight (see Table I). Group 2 consisted of 12 patients with gall stones and 30 with tumour compressing the extrahepatic biliary tree. Six of these tumours were metastatic -

TABLE III Results for red cell phospholipids

\begin{tabular}{|c|c|c|c|c|c|c|}
\hline & \multicolumn{2}{|c|}{ Group 1: controls $(n=42)$} & \multicolumn{2}{|c|}{ Group 2: jaundiced $(n=42)$} & \multirow[b]{2}{*}{$p$} & \multirow[b]{2}{*}{$\begin{array}{l}\text { Ratio of } \\
\text { jaundice: control }\end{array}$} \\
\hline & Mean & $\begin{array}{l}95 \% \text { Confidence } \\
\text { intervals }\end{array}$ & Mean & $\begin{array}{l}95 \% \text { Confidence } \\
\text { intervals }\end{array}$ & & \\
\hline $16: 0$ & 28.03 & $(26.05$ to 30.00$)$ & $36 \cdot 70$ & $(34 \cdot 26$ to $39 \cdot 14)$ & $<0.001$ & $1 \cdot 31$ \\
\hline $18: 0$ & $12 \cdot 85$ & $(11.80$ to 13.90$)$ & 11.02 & $(10.21$ to 11.83$)$ & $<0.010$ & 0.86 \\
\hline $18: \ln -9$ & $19 \cdot 36$ & $(18.13$ to 20.58$)$ & 20.95 & $(19.78$ to $22 \cdot 11)$ & NS & 1.08 \\
\hline $18: 2 n-6$ & $12 \cdot 00$ & (11.06 to 12.94$)$ & 11.69 & $(10.54$ to 12.84$)$ & NS & 0.97 \\
\hline $20: 2 n-6$ & 0.43 & $(0.28$ to 0.59$)$ & 0.57 & $(0.42$ to 0.71$)$ & NS & $1 \cdot 32$ \\
\hline $20: 3 n-6$ & 1.35 & $(1.16$ to 1.54$)$ & 0.86 & $(0.69$ to 1.04$)$ & $<0.001$ & 0.64 \\
\hline $20: 4 n-6$ & $12 \cdot 41$ & $(10.64$ to $14 \cdot 17)$ & $7 \cdot 18$ & (5.63 to 8.73$)$ & $<0.001$ & 0.58 \\
\hline $22: 4 n-6$ & 1.66 & $(1.40$ to 1.92$)$ & 0.91 & $(0.68$ to 1.15$)$ & $<0.001$ & 0.55 \\
\hline $20: 5 n-3$ & 0.98 & $(0.71$ to 1.26$)$ & 0.47 & $(0.30$ to 0.64$)$ & $<0.002$ & 0.48 \\
\hline $22: 5 n-3$ & $1 \cdot 74$ & (1.40 to 2.07$)$ & 0.85 & $(0.55$ to 1.14$)$ & $<0.001$ & 0.49 \\
\hline $22: 6 n-3$ & 4.91 & (3.87 to 5.94$)$ & $2 \cdot 47$ & $(1.67$ to 3.27$)$ & $<0.001$ & 0.50 \\
\hline SFA & $41 \cdot 29$ & (38.71 to 43.87 ) & $48 \cdot 40$ & $(45.81$ to 50.99$)$ & $<0.001$ & $1 \cdot 17$ \\
\hline MUFA & $20 \cdot 32$ & $(19.06$ to 21.59$)$ & 23.73 & (22.38 to 25.08$)$ & $<0.001$ & $1 \cdot 17$ \\
\hline PUFA & $36 \cdot 41$ & $(32.47$ to 40.35$)$ & $25 \cdot 81$ & (22.16 to 29.46$)$ & $<0.001$ & $0 \cdot 71$ \\
\hline DBI & 1.52 & $(1.36$ to 1.68$)$ & 1.08 & $(0.94$ to 1.22$)$ & $<0.001$ & $0 \cdot 71$ \\
\hline Total $(n-6)$ & $28 \cdot 33$ & $(25.69$ to 30.96$)$ & 21.53 & (18.98 to 24.08 ) & $<0.001$ & $0 \cdot 76$ \\
\hline Total (n-3) & 8.07 & $(6.51$ to 9.62$)$ & $4 \cdot 27$ & $(3.02$ to 5.51$)$ & $<0.001$ & 0.53 \\
\hline 18-carbon-PUFA & $12 \cdot 44$ & (11.53 to 13.35$)$ & $12 \cdot 19$ & (11.07 to 13.30$)$ & NS & 0.98 \\
\hline 20-carbon-PUFA & $15 \cdot 19$ & (13.14 to $17 \cdot 23)$ & $9 \cdot 10$ & ( 7.33 to 10.86$)$ & $<0.001$ & $0 \cdot 60$ \\
\hline 22-carbon-PUFA & 10.52 & $(8.75$ to 12.29$)$ & $5 \cdot 37$ & ( 3.80 to 6.95$)$ & $<0.001$ & 0.51 \\
\hline
\end{tabular}




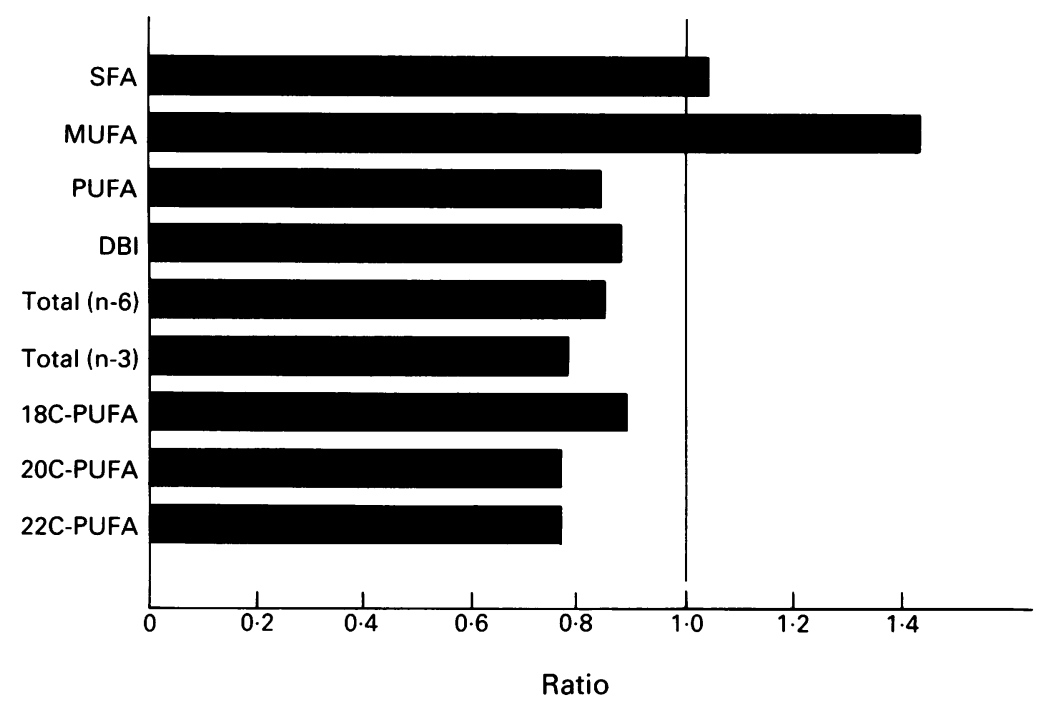

Figure 1: Ratios of mean results from group 2 against group 1 plasma phospholipid fatty acids. The ratios shown are from Tables I and II. They are the ratio of the means for the jaundiced patients (group 2) to the controls (group 1). Tables I and II show the degree of statistical significance of these changes. SF $A=$ saturated fatty acids, MUFA = monounsaturated fatty acids, PUFA = polyunsaturated fatty acids.

from stomach $(n=2)$, breast $(n=1)$, oesophagus $(n=1)$, rectum $(n=1)$, and from an unknown primary $(n=1)$. The site of the primary tumours, in the other 24 patients in group 2, were pancreas $(n=13)$, bile duct $(\mathrm{n}=8)$, ampulla $(\mathrm{n}=2)$, and gall bladder $(n=1)$. Table I shows the liver function tests for the jaundiced patients. As stated previously, the liver function tests of the patients in group 1 were normal.

Tables II and III show the results as molar percentages, except the double bond index, which has no units. There are many highly significant abnormalities, and the general pattern of these can be seen graphically in Figures 1 and 2, where the ratios of group 2 and group 1 are shown.

Separate, and similar, statistical analysis was done comparing the group 2 patients with malignant disease and those with benign disease. No statistically significant differences were found (analysis not shown).

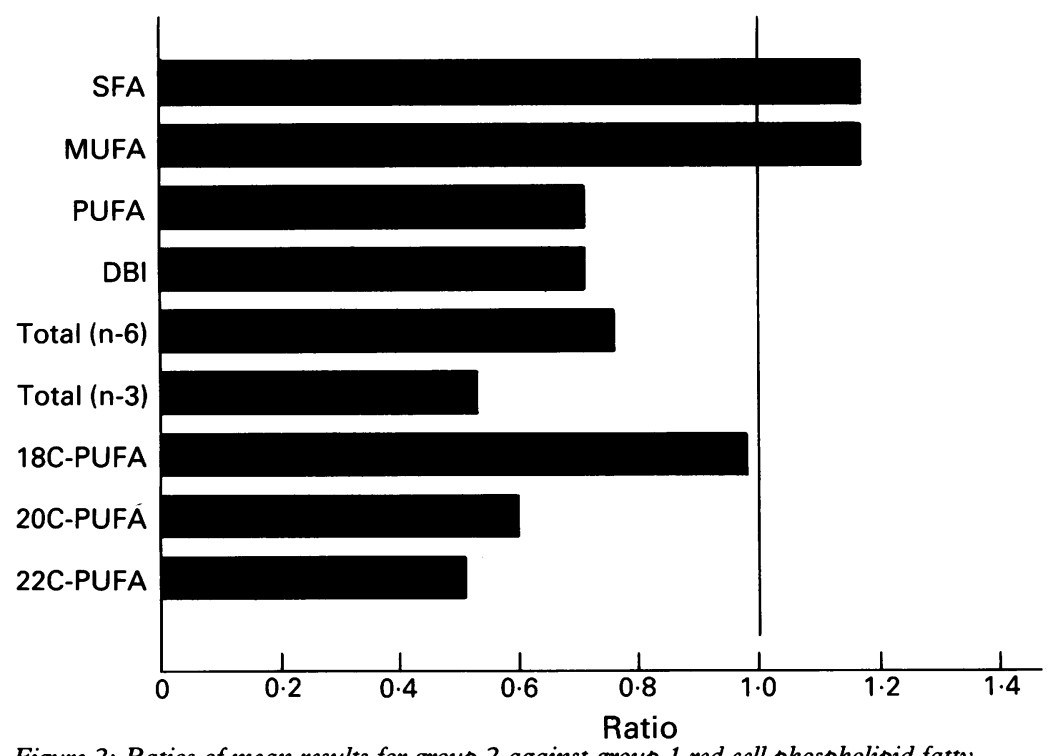

Figure 2: Ratios of mean results for group 2 against group 1 red cell phospholipid fatty acids. The ratios shown are from Tables I and II. They are the ratio of the means for the jaundiced patients (group 2) to the controls (group 1). Tables I and II show the degree of statistical significance of these changes. Abbreviations as in Figure 1.

\section{Discussion}

Fatty acids are important for their influence on membrane function and as substrates for eicosanoid production. In each case the phospholipid fraction is crucial. Plasma and red cell phospholipid fatty acids, are known to reflect tissue levels ${ }^{11}$ and are much less susceptible to short term dietary changes than, for instance, unesterified or triglyceride fatty acids. Despite their importance, it has been difficult to establish normal values, and different groups have reported different results. ${ }^{12} 13$ This may be because of geographical differences or possibly because of longterm dietary customs. ${ }^{14}$ Studies must thus use comparisons with local controls.

The shift in the pattern of fatty acids from polyunsaturated to more saturated ones, in the patients with jaundice, occurred in both red cell and plasma phospholipid. The low double bond index characterises this change. Such changes, if reflected in other tissues, are known to affect membrane fluidity, and thus physical behaviour and enzyme function. ${ }^{15}$ The more noticeable fall in longer polyunsaturated fatty acids - that is, 22-carbon - may further affect function by changing membrane thickness.

The eicosanoids are oxygenated polyunsaturated fatty acid metabolites, and include prostanoids and leukotrienes. The three important 20-carbon precursors - arachidonic acid (20:4n-6), dihomo $\gamma$ linolenic acid $(20: 3 n-6)$, and eicosapentaenoic acid (20: $5 n-3)$ - were all lower in the jaundiced group. Thus total 20-carbon polyunsaturated fatty acids were also lower.

Cells of the reticuloendothelial system are particularly sensitive to changes in membrane phospholipid fatty acid composition. Thus phagocytic function, ${ }^{1617}$ cytotoxicity, ${ }^{18}$ and eicosanoid production ${ }^{19}$ are all influenced by changes in membrane fatty acid patterns. Furthermore, the cells of this system are the most important source of the powerful eicosanoids. Extrahepatic cholestatic jaundice has profound effects on reticuloendothelial system function, affecting clearance of carbon particles, ${ }^{4}$ colloid, ${ }^{6}$ bacteria, ${ }^{5}$ and microaggregated albumin, ${ }^{7}$ as well as monokine production. ${ }^{8}$ Similar changes occur when membrane phospholipid fatty acids become more saturated. The rise in fatty acid saturation that has been shown in this study, may thus explain some of the reticuloendothelial system dysfunction in extrahepatic cholestatic jaundice.

The absence of any significant differences between the malignant and benign jaundiced patients suggests that the effect results from biliary obstruction rather than the cause of the extrahepatic cholestatic jaundice.

The aetiology of these changes was not investigated in this study. Possibilities, however, must include a change in the function of hepatic fatty acid desaturase enzymes, and malabsorption. The desaturase enzymes are sensitive to many factors and seem to be the rate limiting steps in the metabolism of 18-carbon polyunsaturated fatty acids, through to longer more unsaturated fatty acids. ${ }^{20}$ Changes 
in diet only effect phospholipid fatty acids if dietary fat is severely restricted over a prolonged period. In fact, stores of polyunsaturated fatty acids in adipose tissue are very large compared with daily requirements. ${ }^{21} \mathrm{~A}$ further possible explanation of the changes is the damaging effect of high tissue bile acid concentrations on membrane phospholipid. ${ }^{22}$

Considerable abnormalities in phospholipid fatty acids have been shown in extrahepatic cholestatic jaundice. They seem to result from biliary obstruction itself, and may explain some of the abnormalities in the reticuloendothelial system function known to occur in jaundice. Correction of these fatty acid abnormalities, provides a novel way of trying to improve the outcome of these patients. Further evaluation of this approach should be undertaken.

We are grateful for the technical support of the staff at the Efamol Research Institute. We also acknowledge the statistical advice of Dr Tim Peters of the University of Wales College of Medicine, Cardiff.

This work was supported by a grant from Scotia Pharmaceuticals, Woodbridge Meadows, Guildford, Surrey. Pharmaceuticals, Woodbridge Meadows, Guildford, Surrey. Parts of this study have been published in abstract form $-H P B$ Surgery $1990 ; 2: 213 ; B r \mathcal{F}$ Surg $1991 ; 78: 1505$. This work
forms part of a thesis accepted by the University of London for forms part of a thesis accepted by the University
the degree of Master of Surgery, for Mr Scriven.

1 Williams RD, Elliot DW, Zollinger RM. The effect of hypotension in obstructive jaundice. Arch Surg 1960; 81: $334-40$.

2 Dixon JM, Armstrong CP, Duffy SW, Elton RA, Davies GC. Upper gastrointestinal bleeding: a significant complication after surgery for relief of obstructive jaundice. Ann Surg 1984; 199: 271-5.

3 Greig JD, Krukowski ZH, Matheson NA. Surgical morbidity and mortality in one hundred and twenty-nine patients with obstructive jaundice. Br f Surg 1988; 75: 216-9.

4 Halpern BN, Biozzi G, Nicol T, Bilbey DLJ. Effect of experimental biliary obstruction on the phagocytic activity of the reticuloendothelial system. Nature 1957; 180: 503-4.
5 Katz S, Grosfield JL, Gross K, Plager DA, Ross D, Rosenthal RS, et al. Impaired bacterial clearance and trap ping in obstructive jaundice. Ann Surg 1984; 199: 14-20. 6 Tanaka N, Ryden S, Berqvist L, Christensen P, Bengmark $S$. Reticuloendothelial function in rats with obstructive jaundice. Br ₹ Surg 1985; 72: 946-9.

7 Pain JA. Reticuloendothelial function in obstructive jaundice. Br f Surg 1987; 74: 1091-4.

8 Puntis MCA, Jiang WG. Polyunsaturated fatty acids modify in vitro monocyte secretory function in obstructive jaundice. Br ₹ Surg 1991; 78: 1499.

9 Holman RT. Nutritional and functional requirements for essential fatty acids. Prog Clin Biol Res 1986; 222: 211-28.

10 Manku MS, Horrobin DF, Morse N. Fatty acids in plasma and red cell membranes in normal humans. Lipids 1983 18: $906-8$.

11 Paulsrud JR, Pensler L, Whitten CF, Stewart S, Holman RT. Essential fatty acid deficiency in infants induced by fat-free intravenous feeding. Am $\mathcal{F}$ Clin Nutr 1972; 25 897-904.

12 Holman RT, Smythe L, Johnson S. Effect of sex and age on fatty acid composition of human serum lipids. $\mathrm{Am} \mathrm{F}$ Clin Nutr 1979; 32: 2390-9.

13 Love WC, Cashell A, Reynolds M, Callaghan N. Linoleate and fatty-acid patterns of serum lipids in multiple sclerosis and other diseases. BMF 1974; 3: 18-21.

14 Manku MS, Horrobin DF, Morse N. Fatty acids in plasma and red cell membranes in normal humans. Lipids 1983; 18: $906-8$.

15 Stubbs $\mathrm{CD}$, Smith $\mathrm{AD}$. The modification of mammalian membrane polyunsaturated fatty acid composition in relation to membrane fluidity and function. Biochim Biophys Acta 1984; 779: 89-137.

16 Schroitt A, Gallily R. Macrophage fatty acid composition and phagocytosis: effect of unsaturation on cellula phagocytic activity. Immunology 1979; 36: 199-205.

17 Mahoney EM, Scott WA, Landsberger FR, Hamill AL, Cohn ZA. Influence of fatty acyl substitution on the composition and function of macrophage membranes. 7 Biol Chem 1980; 255: 4910-7.

18 Schlager SI, Madden LD, Meltzer MS, Bara S, Mamula MJ. Role of macrophage lipids in regulating tumoricidal MJ. Role of macrophage lipids in regu

19 Billiar TR Maddaus MA, West MA, Curran RD, Wells CA, Simmons RL. Intestinal Gram negative bacterial overgrowth in vivo augments the in vitro response of Kupffer cells to endotoxin. Ann Surg 1988; 208: 532-9.

20 Brenner RR. Nutritional and hormonal factors influencin desaturation of essential fatty acids. Prog Lipid Res 1982, 20: 41-7.

21 Connor WE. Pathogenesis and frequency of essential fatty acid deficiency during total parenteral nutrition. $A n n$ Intern Med 1975; 83: 895-6.

22 Coleman R. Bile salts and biliary lipids. Biochem Soc Trans 1987; 15: 68S-80S. 